\title{
Analysis of Trend of Malaria Prevalence in the Ten Asian Countries from 2006 to 2011: A Longitudinal Study
}

\author{
Shongkour Roy ${ }^{1}$ and Tanjina Khatun ${ }^{2}$ \\ ${ }^{1}$ Population Council, House No. 15B, Road No. 13, Gulshan, Dhaka 1212, Bangladesh \\ ${ }^{2}$ Department of Social Work, Masters Student, Government Bangla College, Mirpur 1, Dhaka 1216, Bangladesh \\ Correspondence should be addressed to Shongkour Roy; sankar1604@gmail.com
}

Received 14 September 2015; Revised 11 November 2015; Accepted 12 November 2015

Academic Editor: Polrat Wilairatana

Copyright (c) 2015 S. Roy and T. Khatun. This is an open access article distributed under the Creative Commons Attribution License, which permits unrestricted use, distribution, and reproduction in any medium, provided the original work is properly cited.

\begin{abstract}
Background. To control the malaria mortality, the global and national communities have worked together and produced impressive results in the world. Some of the Asian counties' malaria mortality rate is more compared to countries with high health facilities around the world. This paper's main aim is to describe trend of malaria cases and mortality in 10 Asian countries using the World Health Organization data. Methods. Malaria mortality data was collected systematically from WHO and UN database for the period 2006-2011. We estimated malaria mortality by age and countries. We also explored the dynamic relationships among malaria death rate, total populations, and geographical region using a map. During 2006-2011, the average malaria death per 10,000 population of all ages was 0.239 (95\% CI 0.104 to 0.373 ), of children aged less than 5 year 1.143 ( 0.598 to 1.687 ), and of age greater than 5 years 0.089 (0.043 to 0.137) in Asian countries. Malaria prevalence per 10,000 populations steadily decreased from 486.7 in 2006 to 298.9 in 2011. Conclusion. The findings show that malaria mortality is higher for children aged less than 5 years compared with with adults selected in Asian countries except Sri Lanka.
\end{abstract}

\section{Introduction}

Since the 1950s, the global health community has focused on eradication campaign to eliminate malaria and malaria related death all over the world [1]. But it failed globally because of some problems including the lack of innovative research and leaderships, the resistance of mosquitoes to insecticides used to kill them, the resistance of malaria parasites to drugs used to treat them, and implementation difficulties. The priority accorded to reductions of malaria mortality in developing countries is shown by its choice as the fourth Millennium Development Goals (MDGs). Much of recent malaria related studies have focused on infant mortality [2] and young children's and adult's exposure to the disease [3] and to some extent the impact on pregnant women [4], without classifying the malaria situation of other subgroups population. Scanty studies have looked specifically at the effect of malaria on adult and old-age people [5] and mobile group population [6]. A lot of data have been taken from heath facilities at different levels that may be dominated by patterns of health services utilization rather than clearly representing malaria patterns within communities [7]. Some works have taken any forms of data which are perhaps available and built to generalize patterns of malaria burden using proper statistical modeling techniques [8] and others have in-depth network members who maintain population surveillance in Health and Demographic Surveillance System sites across Africa and Asia [9].

Despite these efforts and visibility, there was broad concern that malaria remains a major cause of death in Asia [10] and much of infectious morbidity and $90 \%$ of malaria mortality are considered to be in many parts of Africa [11]. Although a lot of tools have been developed for malaria control in Asia, it has been argued that the enormous disease burden due to malaria is grossly underestimated [12]. In 2011, about 1.33 billion people or $75 \%$ of the region's total population resided in areas that were at risk of malaria in Asia. Among them there were 2144849 confirmed malaria cases and 1819 malaria deaths reported by the national malaria control programmes in Asia [13]. Malaria control and 
TABLE 1: Variables with measures and data sources.

\begin{tabular}{lc}
\hline Variables with measures & Sources \\
\hline $\begin{array}{l}\text { Malaria reported case (number) } \\
\text { Malaria death in children aged less } \\
\text { than 5 years (number) }\end{array}$ & World Data (World Bank, \\
$\begin{array}{l}\text { Malaria death in children aged greater } \\
\text { than 5 years (number) }\end{array}$ & UN Data (2011) \\
$\begin{array}{l}\text { Malaria death in all ages group } \\
\text { (number) }\end{array}$ & UN Data (2011) \\
$\begin{array}{l}\text { Total population aged less than 5 years } \\
\text { (number) }\end{array}$ & World Bank, 2011 (HNPS) \\
$\begin{array}{l}\text { Total population aged greater than 5 } \\
\text { years (number) }\end{array}$ & World Bank, 2011 (HNPS) \\
\begin{tabular}{l} 
Total population (number) \\
\hline
\end{tabular} & WDI (2011) \\
\hline
\end{tabular}

elimination in Southeast Asia reported that the 11 member countries in the WHO Southeast Asia region and among them 10 are endemic to malaria. Maldives has been malariafree since 1984 [14] in south Asia.

In Asia, there have been significant malaria control efforts in recent years but it is unclear what impact they have had and six countries, Bhutan, Democratic People's Republic of Korea, Indonesia, Nepal, Sri Lanka, and Thailand, are aiming for malaria elimination as a longer-term goal. Sri Lanka is already in the elimination phase [15] and subnational malaria elimination is progressing well in Indonesia and Thailand [16]. This paper provides estimated malaria prevalence and mortality by age and country for 2006 to 2011. In addition, it allows us to produce maps of all ages' group mortality rate adjusted with total population.

\section{Materials and Methods}

For the analysis subjects of this study we cover 10 countries out of 50 Asian counties. These countries have the highest malaria prevalence rate and close geographical region and fought against malaria for several decades. In this paper, to address the objective, our main aim is to estimate malaria mortality rate and its trend in countries over the said time period. The main sources of the longitudinal data are the World Health Organization and UN database. We utilize two sources (Table 1) of data to create trend of falciparum malaria mortality children under 5 years, children greater than 5 years, and all ages group population over the period 20062011 in Asian countries. All data has been publically available. The first task was the calculation of malaria mortality in Asian countries by age. The WHO database provides this malaria related death data by country and year. However, since some of this data was missing, we also created a second task to determine malaria mortality in Asian countries using the United Nation database. If a country was missing a value for malaria mortality in the $\mathrm{WHO}$ data, in that case, we replace that value of malaria mortality with the one from the UN data. The total population in million was collected from the World Development Indicator database. WHO and UN database provide good quality data; in previous studies many authors used multiple data sources that we also used in this study.

We analyzed descriptive statistics and trend of malaria mortality. The descriptive statistics are prevalence rate per 10,000 populations and death rate per 10,000 populations for all age. Prevalence rate is calculated using the number of malaria reported cases divided by total population with multiplying 10,000 populations for each country and year. Similarly, we also determined a death rate per 10,000 populations for all ages using the number of malaria attributed death divided by total population with multiplying 10,000 populations for each country and year.

In view of the differential patterns of malaria mortality, we analyzed the data into three age groups: aged under five years, aged greater than five years, and all ages using Stata software version 12.0 (StataCorp LP, Lakeway Drive College Station, Texas, USA). To identify summary measures of malaria related death in each country we estimated mean and standard deviation with confidence interval at 95\% level of significance. The confidence interval indicates that there is a $95 \%$ probability of malaria death that encompasses the true values mean of malaria mortality at different age groups. We also exported the maps to view the geostatistical relationship between death rate for all ages and total population within countries.

\section{Results}

During 2006-2011, the prevalence rate per 10,000 people for Bangladesh was raised from 2.308 to 3.440, Myanmar from 43.573 to 96.261 , Republic of Korea from 2.684 to 3.140, and Timor-Leste from 373.566 to 167.866. Again for Bhutan it decreased from 27.687 to 2.628 , India from 15.428 to 10.555 , Indonesia from 15.118 to 10.589 , Nepal from 1.563 to 0.751 , Sri Lanka from 0.298 to 0.059 , and Thailand from 4.503 to 3.581 (Table 2). Compared to these major Asian countries, Myanmar had one of the highest prevalence rate of increase in malaria related to prevalence rate within this time period (Table 2).

The death rate per 10,000 people for India increased from 0.068 to 0.069 and for Indonesia from 0.100 to 0.123 . On the other hand death rate for Bangladesh is decreased from 0.120 to 0.055 , Bhutan from 0.133 to 0.014 , Myanmar from 0.531 to 0.288 , Nepal from 0.024 to 0.005 , Sri Lanka from 0.001 to 0.000 , Thailand from 0.023 to 0.012 , and Timor-Leste from 2.642 to 0.935 . The effective death rate change has been conducted in Sri Lanka and Republic of Korea within this time period in selected Asian countries.

The malaria reported cases steadily changed in India and notably changed in Sri Lanka (Figure 1) and the number of malaria deaths was decreasing in both children aged greater than 5 and all ages but increasing in younger children aged less than 5 years (Figure 2). The overall rate of malaria prevalence decreased from 486.7 in 2006 to 298.8 in 2011 and death rate also decreased from 3.6 in 2006 to 1.5 in 2011 (Table 2) in Asia. Among ten Asian countries over the time period, the prevalence rate per 10,000 populations is still notably present in Republic of Korea and Sri Lanka but these countries have zero deaths. 
TABLE 2: Country specific malaria prevalence rate per 10,000 people and death rate per 10,000 people (all ages).

\begin{tabular}{|c|c|c|c|c|c|c|c|}
\hline \multirow{2}{*}{ Country(s) } & \multirow{2}{*}{ Indicator(s) } & \multicolumn{6}{|c|}{ Year(s) } \\
\hline & & 2006 & 2007 & 2008 & 2009 & 2010 & 2011 \\
\hline \multirow{2}{*}{ Bangladesh } & Prevalence & 2.308 & 4.159 & 5.821 & 4.344 & 3.758 & 3.440 \\
\hline & Death rate & 0.120 & 0.155 & 0.086 & 0.035 & 0.055 & 0.055 \\
\hline \multirow{2}{*}{ Bhutan } & Prevalence & 27.687 & 11.516 & 4.691 & 13.620 & 6.006 & 2.628 \\
\hline & Death rate & 0.133 & 0.044 & 0.029 & 0.084 & 0.041 & 0.014 \\
\hline \multirow{2}{*}{ India } & Prevalence & 15.428 & 12.853 & 12.869 & 12.946 & 13.065 & 10.555 \\
\hline & Death rate & 0.068 & 0.068 & 0.072 & 0.082 & 0.071 & 0.069 \\
\hline \multirow{2}{*}{ Indonesia } & Prevalence & 15.118 & 14.359 & 11.333 & 11.477 & 9.581 & 10.589 \\
\hline & Death rate & 0.100 & 0.083 & 0.114 & 0.122 & 0.118 & 0.123 \\
\hline \multirow{2}{*}{ Myanmar } & Prevalence & 43.573 & 79.708 & 94.618 & 91.608 & 87.736 & 96.261 \\
\hline & Death rate & 0.531 & 0.420 & 0.425 & 0.385 & 0.335 & 0.288 \\
\hline \multirow{2}{*}{ Nepal } & Prevalence & 1.563 & 1.671 & 1.117 & 0.926 & 0.932 & 0.751 \\
\hline & Death rate & 0.024 & 0.005 & 0.006 & 0.006 & 0.006 & 0.005 \\
\hline \multirow{2}{*}{ Republic of Korea } & Prevalence & 2.684 & 0.894 & 3.394 & 2.975 & 2.711 & 3.140 \\
\hline & Death rate & 0.000 & 0.000 & 0.000 & 0.000 & 0.000 & 0.000 \\
\hline \multirow{2}{*}{ Sri Lanka } & Prevalence & 0.298 & 0.099 & 0.321 & 0.260 & 0.306 & 0.059 \\
\hline & Death rate & 0.001 & 0.000 & 0.000 & 0.000 & 0.000 & 0.000 \\
\hline \multirow{2}{*}{ Thailand } & Prevalence & 4.503 & 4.894 & 4.185 & 4.288 & 4.699 & 3.581 \\
\hline & Death rate & 0.023 & 0.021 & 0.021 & 0.015 & 0.017 & 0.012 \\
\hline \multirow{2}{*}{ Timor-Leste } & Prevalence & 373.566 & 504.890 & 475.549 & 428.144 & 421.330 & 167.866 \\
\hline & Death rate & 2.642 & 2.103 & 1.512 & 1.315 & 1.330 & 0.935 \\
\hline \multirow{2}{*}{ Ten Asian countries } & Prevalence & 486.728 & 635.043 & 613.898 & 570.589 & 550.123 & 298.970 \\
\hline & Death rate & 3.642 & 2.900 & 2.263 & 2.044 & 1.974 & 1.500 \\
\hline
\end{tabular}

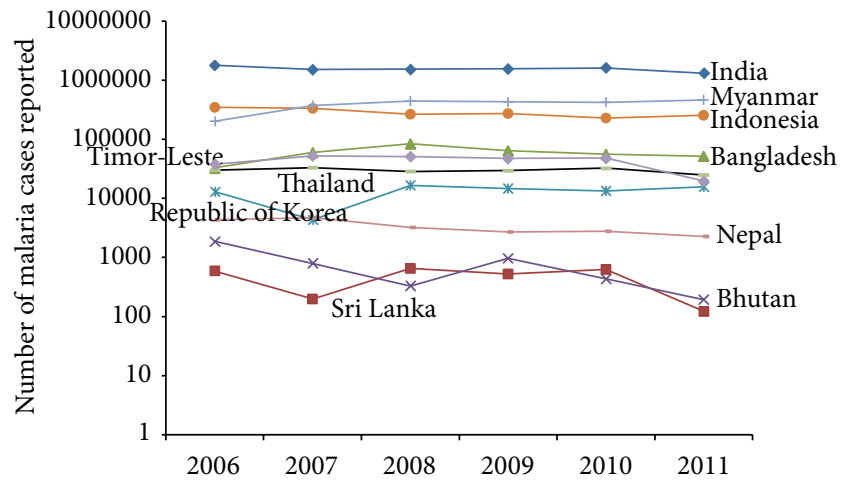

Figure 1: Trend of malaria reported cases (all ages) in Asian countries over 2006-2011.

Figure 3 showed the trend of number of malaria deaths under the age of 5 with zero deaths in Sri Lanka and Republic of Korea and consistent decrease in Nepal, Thailand, and also Timor-Leste. On the other hand, other selected countries followed an upward trend. When we considered malaria death age greater than 5 , different pictures showed that zero deaths in Sri Lanka and Republic of Korea and others countries have a decreased trend over the period (Figure 4).

Between 2006 and 2011, the highest average malaria death rate in younger children aged less than 5 years of 6.867

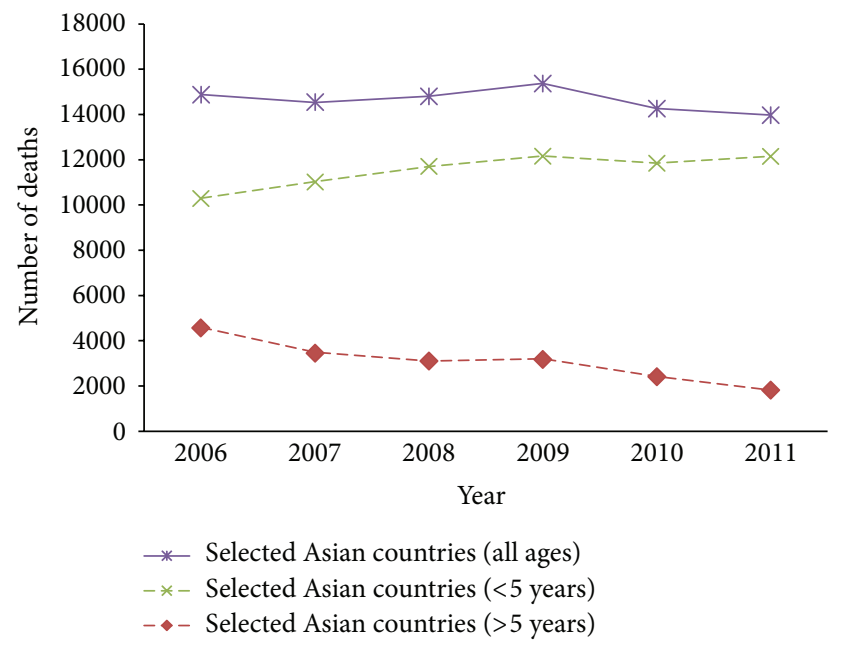

Figure 2: Trend of malaria deaths in geographical region over 20062011.

(95\% CI 4.767-8.969), children aged greater than 5 years of 0.539 (95\% CI $0.286-0.793$ ), and all ages of 1.639 (95\% CI 0.987-2.292) was in Timor-Leste and the lowest was in Korea Republic (Table 3). Similarly, the highest malaria death rate per 10,000 population in Timor-Leste was 0.935 and in Republic of Korea was zero (Table 2, Figure 5) in 2011. 


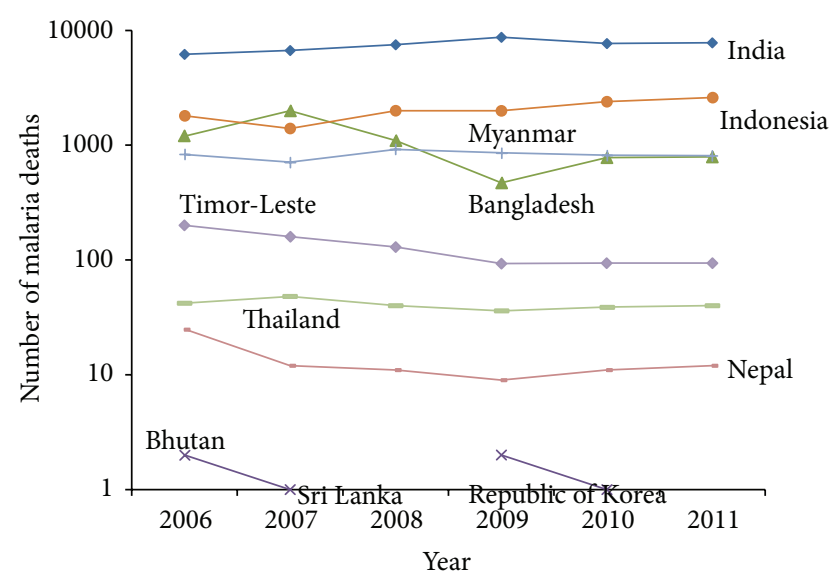

FIGURE 3: Trend of malaria reported death (aged $<5$ year) in countries over 2006-2011.

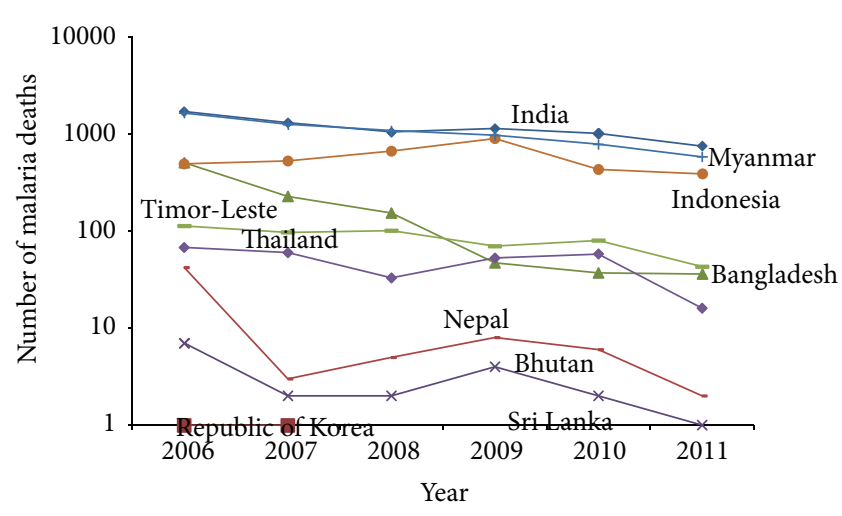

Figure 4: Trend of malaria reported death (aged > 5 year) in countries over 2006-2011.

The number of children deaths due to malaria in Asia has been steadily decreasing since 2009 (Figure 2). Contrary to this trend, the number of deaths due to malaria in Asian individuals aged greater than 5 years accounts for a significant decrease (Figure 2). The second highest average malaria death rate in younger children aged less than 5 years of 2.072 (95\% CI 1.885-2.259) was in Myanmar and the third highest of 0.929 (95\% CI 0.733-1.125) was in Indonesia (Table 3). But the third highest average malaria death rate in children aged greater than 5 years of 0.048 (95\% CI $0.009-0.086)$ was in Bhutan (Table 3). When we looked at malaria death rate for the all age's group people in Table 3 , the patterns that arose for the first, second, and third highest countries average malaria related deaths rate are Timor-Leste 1.639 (95\% CI 0.987 2.292), Myanmar 0.397 (95\% CI 0.309-0.486), and Indonesia 0.109 (95\% CI12 0.093-0.126).

\section{Discussion}

Findings from analysis showed that, in the year 2011, on the basis of data pattern and a refined understanding about malaria mortality, malaria is the underlying cause of death for 13970 individuals, including 12150 children aged younger than 5 years and 1820 individuals aged 5 years or older. Since 2006 , we noted that substantial improvement has been made in the combat against malaria, with a $6 \%$ reduction for all ages of malaria deaths in Asia, which was very low with global malaria death reduction rate [17]. However, our findings also show that the substantial acceleration in the decreases of death for ages of 5 years or older is $60 \%$ especially in Asia and provide hope that rapid reduction will be held in near future. The rate of increase of malaria death in children aged younger than 5 years is $18 \%$ since 2006 . This rate of change in malaria mortality of children aged younger than 5 in Asian countries has become greater with previous estimates and does not support ambitious aspirational goals. Malaria mortality rate under 5 aged groups is still high compared to other aged groups in all most selected countries. Malaria death of children younger than 5 years is a serious issue in Asian countries, although a lot of initiatives have been taken to reduce malaria mortality. As new Asian aims for malaria mortality are decreased, it will be necessary to take lessons from these insights but also begin future planning for the evolving and more effective malaria reduction programme. Some achievement of random goals established without exact regard to the distribution of rates of change dominating at the time is a political form that confuses knowledge and acclaim for the substantial progress that has been made to reduce malaria mortality in the past decade. Moreover, accelerated decreases in malaria mortality will be more likely if we strongly maintain commitment for malaria control (zero death) and increase investment for new strategies, and evidence from policy responses in the Asian countries is widely and effectively circulated and implemented. Our future aimed to identify which factors have impact to reduce malaria mortality rate in Asian countries with included wide range of significant indicators.

\section{Conclusions}

The malaria mortality rate is steadily decreasing; moreover malaria is still now a major health hazard in Asia. Malaria prevalence rate in most of the selected Asian countries is not decreasing sharply as we expected and more attention is needed in these countries to control new cases of malaria. Our findings provided potential evidence that these countries' death rate is not increasing compared to increased prevalence rate. Our analysis refined that the children aged less than 5 were more affected by the malaria compared to older ones in Asian countries. Henceforth, children aged less than 5 are more vulnerable than others and scientific community also needs the highest priority to pay attention to this group of population.

\section{Conflict of Interests}

The authors declare that there is no conflict of interests regarding the publication of this paper. 


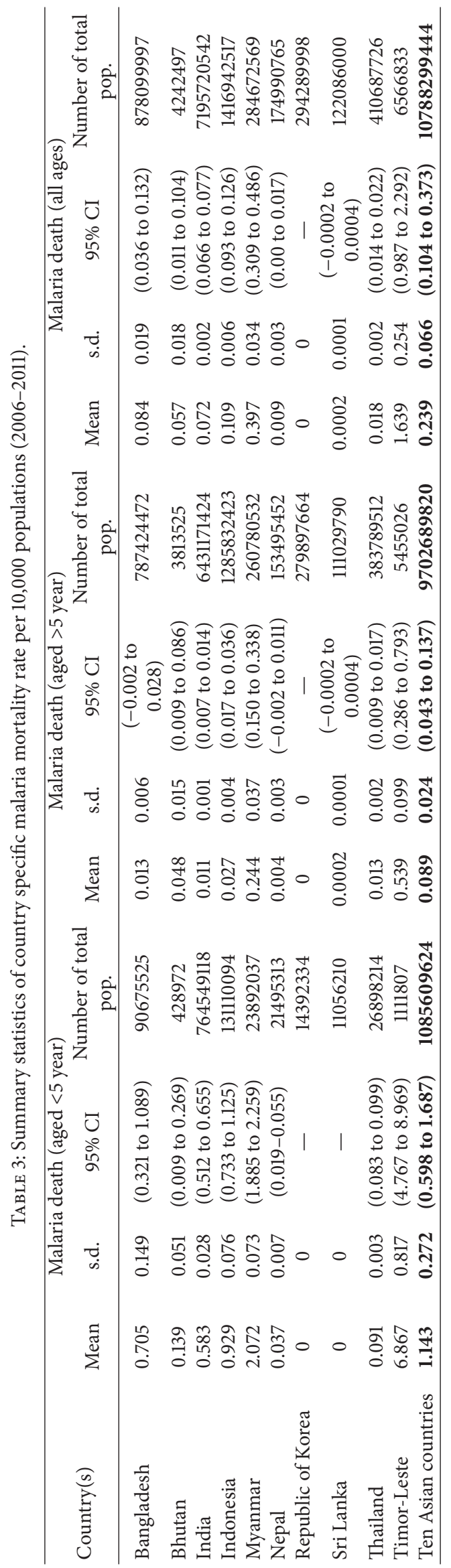




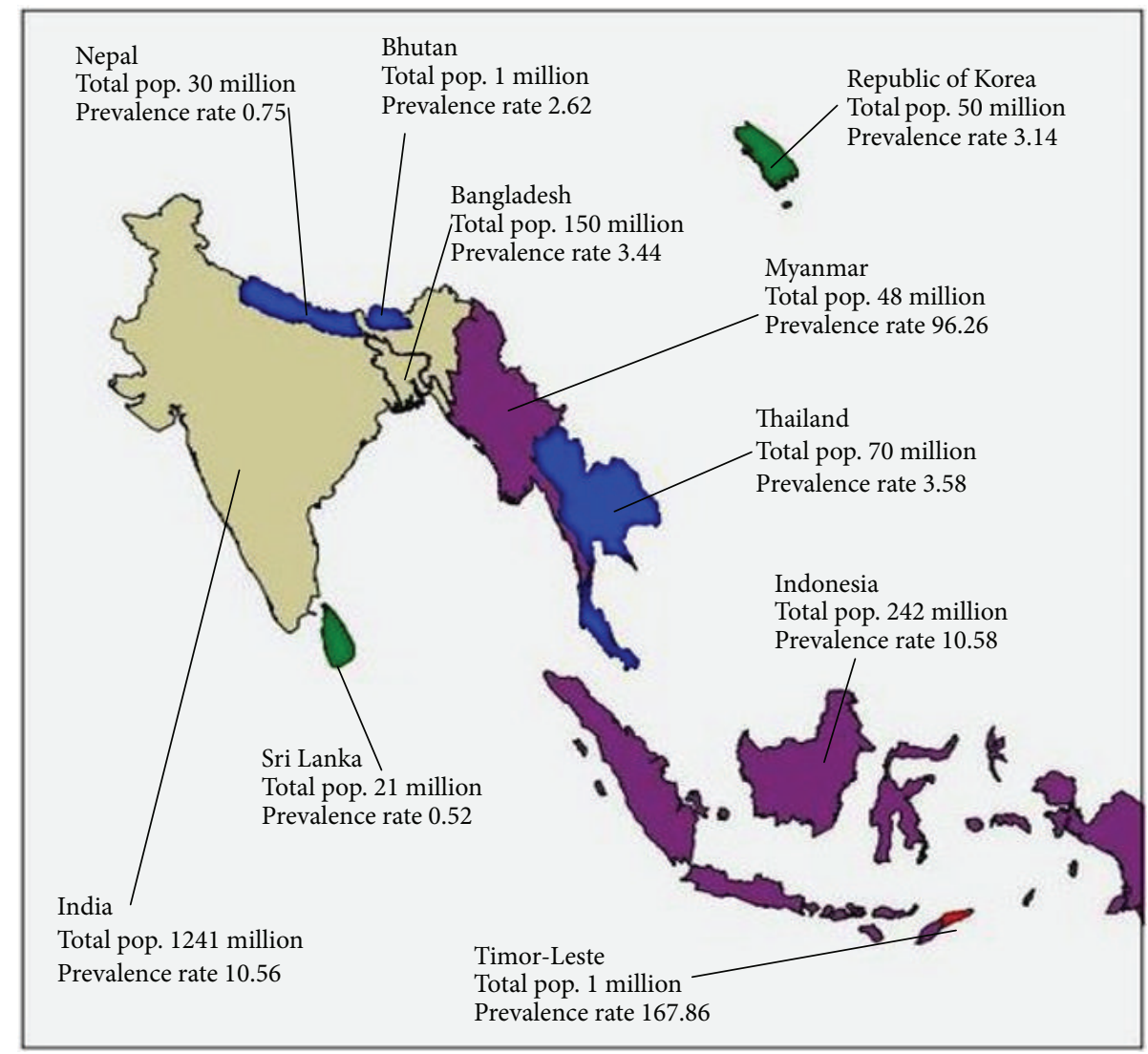

Malaria death rate per 10,000 people (all age group)

0

$0.12-0.29$

$0.01-0.02$

0.94

$0.06-0.07$

Figure 5: Total population and death rate per 10,000 population (all ages), 2011.

\section{Acknowledgment}

The authors thank Taposh for his involvement in the initial stage of the study.

\section{References}

[1] W. P. O’Meara, J. N. Mangeni, R. Steketee, and B. Greenwood, "Changes in the burden of malaria in sub-Saharan Africa," The Lancet Infectious Diseases, vol. 10, no. 8, pp. 545-555, 2010.

[2] A. Gemperli, P. Vounatsou, I. Kleinschmidt, M. Bagayoko, C. Lengeler, and T. Smith, "Spatial patterns of infant mortality in Mali: the effect of malaria endemicity," American Journal of Epidemiology, vol. 159, no. 1, pp. 64-72, 2004.

[3] G. Fink, A. Olgiati, M. Hawela, J. M. Miller, and B. Matafwali, "Association between early childhood exposure to malaria and children's pre-school development: evidence from the Zambia early childhood development project," Malaria Journal, vol. 12, article 12, 2013.

[4] A. K. Amegah, O. K. Damptey, G. A. Sarpong, E. Duah, D. J. Vervoorn, and J. J. K. Jaakkola, "Malaria infection, poor nutrition and indoor air pollution mediate socioeconomic differences in adverse pregnancy outcomes in Cape Coast, Ghana," PLoS ONE, vol. 8, no. 7, Article ID e69181, 2013.

[5] O. A. Sankoh, G. Kynast-Wolf, B. Kouyaté, and H. Becher, "Patterns of adult and old-age mortality in rural Burkina Faso," Journal of Public Health Medicine, vol. 25, no. 4, pp. 372-376, 2003.

[6] J. E. Manning, P. Satharath, J. Gaywee, M. N. Lopez, C. Lon, and D. L. Saunders, "Fighting the good fight: the role of militaries in malaria elimination in Southeast Asia," Trends in Parasitology, vol. 30, no. 12, pp. 571-581, 2014.

[7] E. A. Okiro, L. N. Kazembe, C. W. Kabaria et al., "Childhood malaria admission rates to four hospitals in Malawi between 2000 and 2010," PLoS ONE, vol. 8, no. 4, Article ID e62214, 2013.

[8] J. T. Griffin, N. M. Ferguson, and A. C. Ghani, "Estimates of the changing age-burden of Plasmodium falciparum malaria disease in sub-Saharan Africa," Nature Communications, vol. 5, article 3136, 2014.

[9] P. K. Streatfield, W. A. Khan, A. Bhuiya et al., "Malaria mortality in Africa and Asia: evidence from INDEPTH health and demographic surveillance system sites," Global Health Action, vol. 7, Article ID 25369, 2014. 
[10] R. W. Snow, C. A. Guerra, A. M. Noor, H. Y. Myint, and S. I. Hay, "The global distribution of clinical episodes of Plasmodium falciparum malaria," Nature, vol. 434, no. 7030, pp. 214-217, 2005.

[11] World Health Organization, "World Malaria Report 2013," http://www.who.int/malaria/publications/world_malaria_ report_2013/report/en.

[12] R. J. Maude, A. M. Dondorp, M. A. Faiz et al., "Malaria in southeast Bangladesh: a descriptive study," Bangladesh Medical Research Council Bulletin, vol. 34, no. 3, pp. 87-89, 2008.

[13] Malaria control and elimination in South-East Asia RegionReport, 2011, http://www.wpro.who.int/mvp/documents/docs/ SEARO_fact_sheet_wmd.pdf.

[14] K. Mendis, A. Rietveld, M. Warsame, A. Bosman, B. Greenwood, and W. H. Wernsdorfer, "From malaria control to eradication: the WHO perspective," Tropical Medicine and International Health, vol. 14, no. 7, pp. 802-809, 2009.

[15] N. D. Karunaweera, G. N. Galappaththy, and D. F. Wirth, "On the road to eliminate malaria in Sri Lanka: lessons from history, challenges, gaps in knowledge and research needs," Malaria Journal, vol. 13, article 59, 2014.

[16] R. Bhatia, R. M. Rastogi, and L. Ortega, "Malaria successes and challenges in Asia," Journal of Vector Borne Diseases, vol. 50, no. 4, pp. 239-247, 2013.

[17] C. J. L. Murray, L. C. Rosenfeld, S. S. Lim et al., "Global malaria mortality between 1980 and 2010: a systematic analysis," The Lancet, vol. 379, no. 9814, pp. 413-431, 2012. 


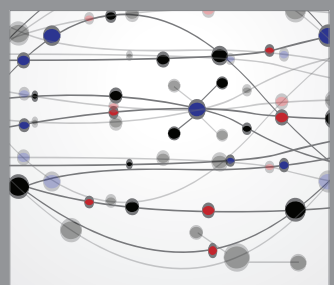

The Scientific World Journal
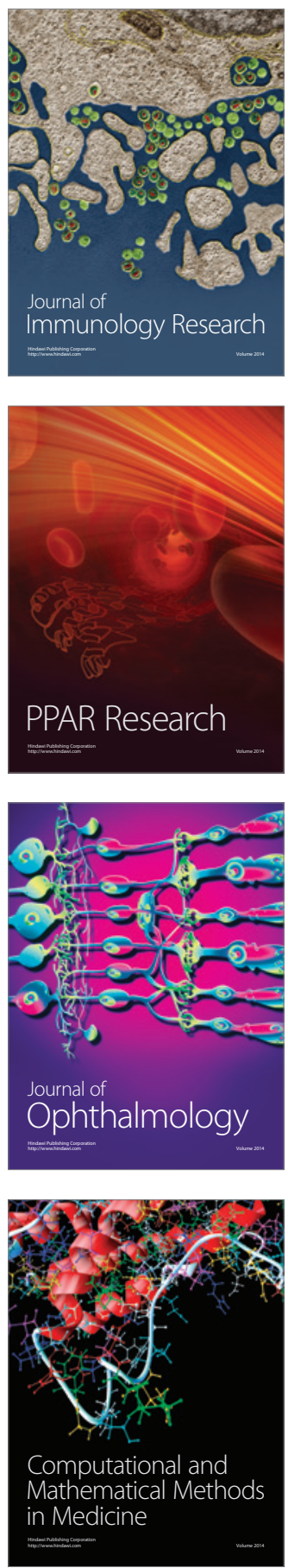

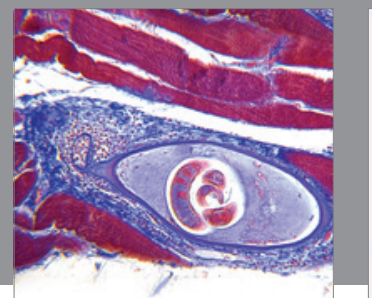

Gastroenterology

Research and Practice
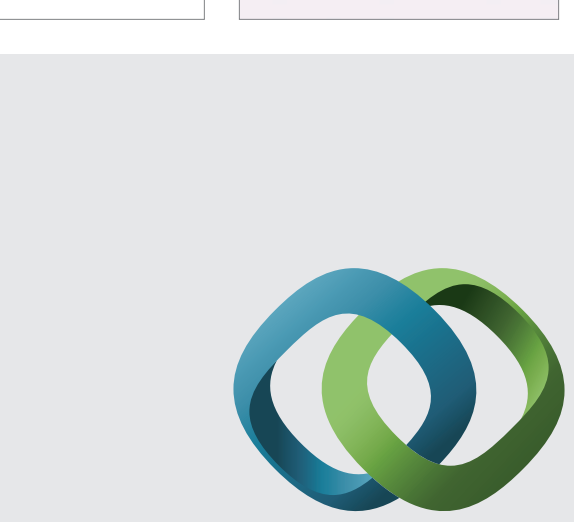

\section{Hindawi}

Submit your manuscripts at

http://www.hindawi.com
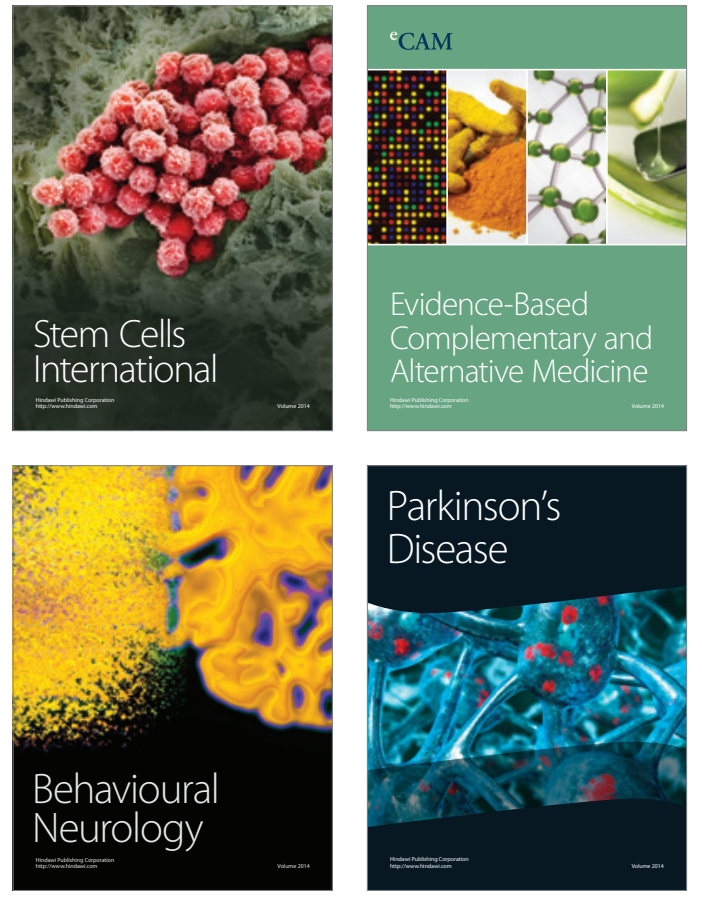
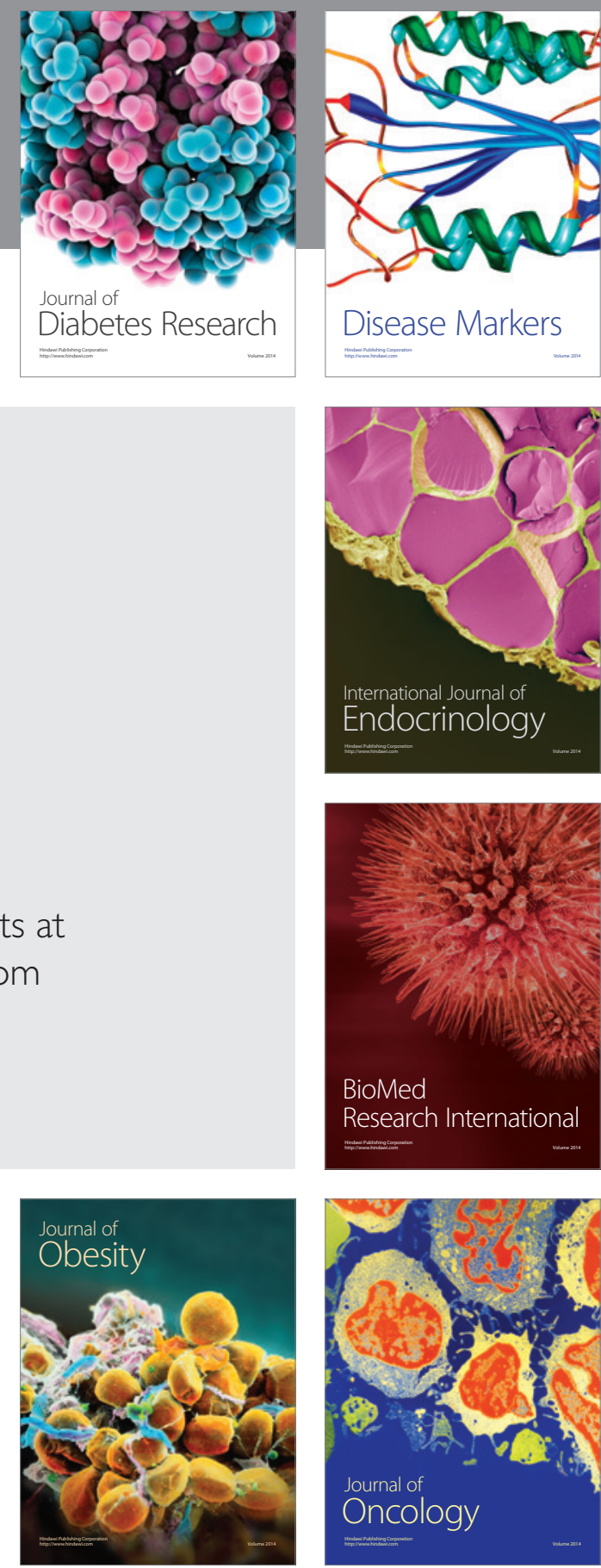

Disease Markers
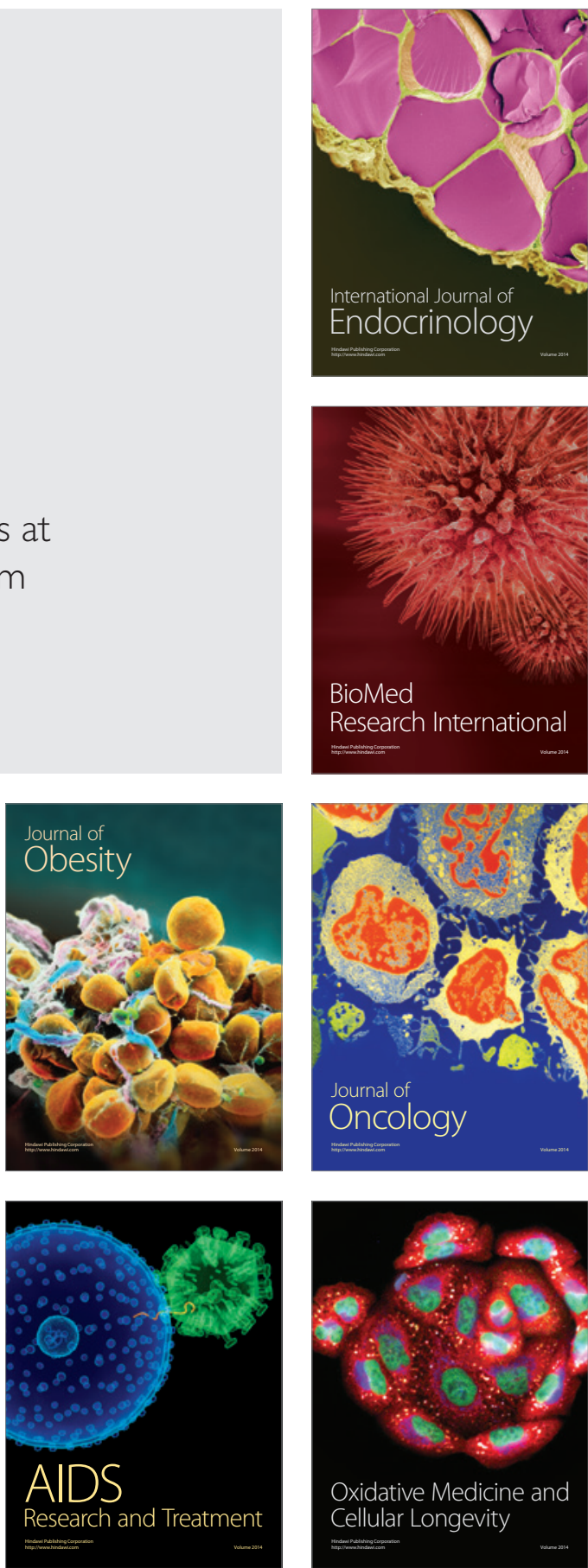